\title{
Estratégias Construtivas Para Adequação da Envoltória de uma Habitação de Interesse Social às Zonas Bioclimáticas Mato-Grossenses
}

\section{Constructive Strategies to Adapt a Low Incoming House Project to the Bioclimatic Zones of Mato Grosso State}

${ }^{1}$ Emeli Lalesca Aparecida da Guarda, ${ }^{2}$ Luciane Cleonice Durante, ${ }^{3}$ Ivan Julio Apolônio Callejas,

${ }^{4}$ Stefany Hoffmann Martins Jorge, ${ }^{5}$ Raphael Pinto Brandão

\begin{abstract}
${ }^{1}$ Mestranda do programa de Pós-graduação em Engenharia de Edificações e Ambiental da Faculdade de Arquitetura, Engenharia e Tecnologia, Universidade Federal de Mato Grosso, Av. Fernando Correa da Costa, 2367, FAET, Cuiabá-MT, (emeliguarda@gmail.com) ${ }^{2}$ Doutora em Física Ambiental, Professor Adjunto IV da Faculdade de Arquitetura, Engenharia e Tecnologia, Universidade Federal de Mato Grosso, Av. Fernando Correa da Costa, 2367, FAET, Cuiabá-MT, (luciane.durante@ hotmail.com)

${ }^{3}$ Doutor em Física Ambiental, Professor Adjunto IV da Faculdade de Arquitetura, Engenharia e Tecnologia, Universidade Federal de Mato Grosso, Av. Fernando Correa da Costa, 2367, FAET, Cuiabá-MT, E-mail:

(ivancallejas1973@gmail.com)

${ }^{4}$ Voluntário de Iniciação Científica, Curso de Arquitetura e Urbanismo, da Faculdade de Arquitetura, Engenharia e Tecnologia, Universidade Federal de Mato Grosso, Av. Fernando Correa da Costa, 2367, FAET, Cuiabá-MT, (stefanyhoffmann@ hotmail.com)

${ }^{5}$ Voluntário de Iniciação Científica, Curso de Arquitetura e Urbanismo, da Faculdade de Arquitetura, Engenharia e Tecnologia, Universidade Federal de Mato Grosso, Av. Fernando Correa da Costa, 2367, FAET, Cuiabá-MT, (raphaelpbrandao@hotmail.com)
\end{abstract}

RESUMO: Pensar as construções habitacionais de forma que se adequem ao clima de Mato Grosso é um exercício interessante de decisões projetuais, uma vez que o estado possui extenso território, com elevadas temperaturas do ar durante o ano todo e também ampla variação higrométrica. Em virtude das características de clima quente, com estações seca e úmida, muitas vezes requerem estratégias projetuais antagônicas. Assim sendo, este artigo objetiva elaborar propostas de readequação da envoltória de uma Habitação de Interesse Social (HIS) considerando os requisitos de desempenho térmico e eficiência energética das quatro zonas bioclimáticas (ZB) do estado de Mato Grosso. Para o estudo foi considerado a orientação de implantação mais desfavorável sob o ponto de vista térmico. A metodologia consiste em identificar das propriedades dos materiais das paredes e coberturas, cores da envoltória e áreas mínimas de iluminação e ventilação natural, para fins comparação com os pré-requisitos bioclimáticos das normas e regulamentos brasileiros e elaboração de propostas de adequação com vistas à obtenção do melhor nível de eficiência energética. As propostas de intervenções para o sistema de vedação vertical utilizadas na readequação do projeto foram o aumento da espessura do reboco para as zonas ZB 5,6 e 7 e inserção de material isolante do tipo poliuretano de $2,5 \mathrm{~cm}$ (EPS) entre a argamassa e tijolo cerâmico para a zona ZB 8. Na o sistema de cobertura, as intervenções foram a inserção de manta isolante de poliuretano de $0,5 \mathrm{~cm}$ com aumento do pé-direito e alteração da posição do forro para as zonas ZB 5 e 8 e adoção de forro de madeira para ZB 7. A contribuição deste estudo reside no fato de evidenciar que é possível adequar a habitação com intervenções construtivas de fácil incorporação nos sistemas originais do projeto, mas com grande contribuição para a sustentabilidade da habitação.

Palavras Chave: Arquitetura bioclimática. Envoltória do edifício. RTQ-R.

ABSTRACT: To think about the housing constructions in such way to adapt them to the Mato Grosso state climates is an interesting design exercise, since the state has an extensive territory, with high air temperatures throughout the year and also wide hygrometric variation. Due to the characteristics of hot climate, with dry and humid seasons, most time it is required antagonistic design strategies. Thus, this article aims to elaborate proposals for the adaptation of the envelope of Low Incoming House (LIH) considering the thermal performance and energy efficiency requirements of the four bioclimatic zones (ZB) of Mato Grosso state. The most unfavorable orientation of implantation was considered from the thermal point of view. The methodology consists of identifying the properties of wall and roof building materials, the envelope color and the requirements of minimum areas for illumination and natural ventilation, as well as, to identify the Brazilian standard bioclimatic prerequisites and efficient energetic regulations and then elaborate adequacy proposals focusing to achieve the highest level of energy efficient. The intervention proposals for the vertical sealing system used in the redesign of the project were to increase plaster thickness for the ZB 5, 6 and 7 zones and to insert a $2.5 \mathrm{~cm}$ 
Guarda, Emeli L. A; et al; Estratégias Construtivas Para Adequação da Envoltória de uma Habitação de Interesse Social às Zonas Bioclimáticas Mato-Grossenses. E\&S - Engineering and Science, (2018), 7:1.

polyurethane insulating material between the mortar and ceramic brick for ZB 8 zone. In the roof system, the interventions were to insert $0.5 \mathrm{~cm}$ polyurethane insulation blanket together with the right foot modification and elevation of the ceiling position for ZB 5 and 8 zones and adoption of wood ceiling, instead of PVC ceiling, for ZB 7 zone. The study contribution lies in the fact that it is possible to adapt the housing project with constructive interventions of easy incorporation to the original systems of the building, but with great contribution to the house sustainability.

Keywords: Bioclimatic architecture. Building envelope. RTQ-R.

\section{INTRODUÇÃOO}

As Habitações de Interesse Social (HIS), assim como as demais edificações, sofrem influência dos diferentes climas dos locais onde são implantadas. No entanto, mesmo tendo sido identificados no Brasil 12 tipos de climas pela classificação Köppen-Geiger (ÁLVARES et al., 2014) em sua vasta extensão territorial, observa-se que os projetos das HIS são padronizados em termos de materiais da envoltória, o que lhes confere desempenho termoenergético nem sempre adequado às cidades em que são implantadas. Nesse contexto, a solução arquitetônica padronizada pode resultar em redução da qualidade de vida dos ocupantes e aumento do consumo de energia devido à necessidade de uso mais intensivo de condicionamento e iluminação artificial, resultando em edifícios de baixa eficiência energética.

Na maioria dos países desenvolvidos, as edificações são projetadas visando atender as os requisitos de sustentabilidade, tanto na concepção quanto para o uso dos espaços. Desta forma, são adotados recursos de aproveitamento da luz natural, uso racional dos sistemas de refrigeração e aquecimento, reciclagem de resíduos, aproveitamento de águas pluviais, reaproveitamento de águas servidas, utilização de energia solar e geração autônoma de eletricidade, dentre outros. Essas construções, comumente denominadas de sustentáveis, verdes ou ecológicas, geralmente demandam maior investimento inicial, com representativa economia ao longo de seu uso e operação.

No Brasil, o custo da implantação de uma edificação sustentável inicial é ainda maior, seja pela incipiência da disponibilidade de tecnologia nacional seja pela de cultura dos profissionais da construção civil para desenvolvimento e avaliação de projetos com este enfoque, bem como execução de obras desse caráter. Pensar o desenvolvimento sustentável no âmbito das habitações de interesse social em nosso país é ainda um desafio maior, somando-se às dificuldades anteriormente citadas, a escassez de recursos destinados ao setor das moradias de baixa renda.

No estado de Mato Grosso, o problema da habitabilidade das habitações de interesse social é ainda mais amplificado, haja vista o rigor climático que se apresenta, com elevadas temperaturas durante o ano todo e grandes variações de umidade ao longo de seu território e durante o ano. A mitigação desse rigor climático por meio de adoção de estratégias de adequação da edificação ao clima pode contribuir de forma decisiva para a minimização do uso intensivo dos sistemas de condicionamento de ar e iluminação artificial, que são inevitavelmente adotados para adequar as condições ambientais às necessidades dos usuários.

A arquitetura bioclimática constitui-se de uma arquitetura integrada ao meio ambiente, sensível ao impacto que causa na natureza e que busca minimizar o consumo energético, e a degradação ambiental. (FRANÇA; CRUCINSKY, 2010). Trata-se de uma abordagem que busca atingir o conforto ambiental por meio da aplicação correta de estratégias específicas para cada região, em prol de melhorias no conforto térmico, acústico e lumínico e, consequentemente, tornando a edificação mais eficiente e proporcionando melhor qualidade de vida aos usuários. Clímaco e Amorim (2008) definem arquitetura bioclimática como: 
Guarda, Emeli L. A; et al; Estratégias Construtivas Para Adequação da Envoltória de uma Habitação de Interesse Social às Zonas Bioclimáticas Mato-Grossenses. E\&S - Engineering and Science, (2018), 7:1.

\begin{abstract}
“(...) arquitetura que se abre para dar entrada e absorver energia solar em regiões ou épocas de temperaturas baixas; é a arquitetura que exclui do sol em épocas ou regiões de temperaturas altas; que atrasa a entrada do calor para as horas mais frias; é aquela que se abriga da radiação solar através da cobertura, ocupa a área de sombra delimitada por ela e se abre completamente para a ventilação dissipar o ar aquecido e a umidade excessiva; enfim, é a arquitetura que tira partido das condições oferecidas pelo ambiente natural para atender às necessidades básicas do seu usuário, o homem na construção de seu abrigo.” (CLÍMACO e AMORIM, 2008, p.01).
\end{abstract}

No Brasil, o conjunto de recomendações e diretrizes construtivas visando à adequação climática de habitações unifamiliares ao conforto ambiental e desempenho térmico é estabelecido pelas normas NBR 15220 (ABNT, 2005a) e NBR 15575 (ABNT, 2013), respectivamente. Já a adequação visando à eficiência energética é dada pelo Regulamento Técnico da Qualidade do Nível de Eficiência Energética de Edifícios Residenciais (INMETRO, 2012). Ambas estabelecem pré-requisitos mínimos de desempenho dos materiais e cores das paredes e coberturas, bem como de áreas de ventilação e iluminação natural baseados nas oito zonas bioclimáticas brasileiras (ZB). Uma vez atendidos os pré-requisitos normativos, as trocas térmicas entre a envoltória e o meio são processadas de forma adequada, minimizando a dependência dos sistemas artificiais de condicionamento térmico e iluminação artificial.

Pesquisas sobre a adequação das edificações ao clima já foram realizadas isoladamente em algumas cidades do estado de Mato Grosso (DURANTE, NOGUEIRA e SANCHES, 2006; PASSOS, DAMASCENO e BARBIRATO, 2008; ROTTA, 2009; MARAFON, LACO e SANCHES, 2014; RIOS, 2015; OLARTECHEA et al., 2015; ASSIS et al., 2016). No entanto, em virtude de sua vasta extensão territorial e da existência de várias zonas bioclimáticas dentro do seu contorno geográfico (zonas 5, 6, 7 e 8), torna-se necessário a utilização de diferentes estratégias construtivas para adequar as edificações ao clima, em especial, as de interesses social, objeto deste estudo.

Com base no acima exposto, este artigo tem por objetivo elaborar propostas de readequação da envoltória de uma Habitação de Interesse Social (HIS) considerando os requisitos de desempenho térmico e eficiência energética das quatro zonas bioclimáticas $(\mathrm{ZB})$ do estado de Mato Grossona na orientação de implantação mais desfavorável sob o ponto de vista térmico.

Contribui-se desta forma com a divulgação de técnicas construtivas adequadas ao enquadramento das edificações quanto aos requisitos técnicos de desempenho térmico e energéticos para os futuros projetos a serem implantados no estado de Mato Grosso.

\title{
2. MATERIAIS E MÉTODOS
}

\subsection{Objeto de estudo e caracterização do clima do estado de Mato Grosso}

A HIS escolhida como objeto do estudo é do tipo unifamiliar, edificação isolada no lote, com área de 39,57 $\mathrm{m}^{2}$, contendo sala/cozinha, banheiro e dois quartos (Figura 1). Esta tipologia de HIS foi amplamente construída no estado de Mato Grosso, o qual abriga quatro das oito zonas bioclimáticas brasileiras (ZB5, ZB6, ZB7 e ZB8).

O clima do estado é caraterizado por Moreno et al. (2005), considerando as chuvas, temperatura e vegetação regional, como: tropical chuvoso, tropical de savana e tropical de altitude, subdividido em quente úmido e subquente úmido, ambos com três meses secos, e subquente semiúmido, com quatro a cinco meses secos (Figuras 2 e 3 ). 
Guarda, Emeli L. A; et al; Estratégias Construtivas Para Adequação da Envoltória de uma Habitação de Interesse Social às Zonas Bioclimáticas Mato-Grossenses. E\&S - Engineering and Science, (2018), 7:1.

Figura 1 - Edificação utilizada como objeto de estudo

a) Planta-baixa da HIS

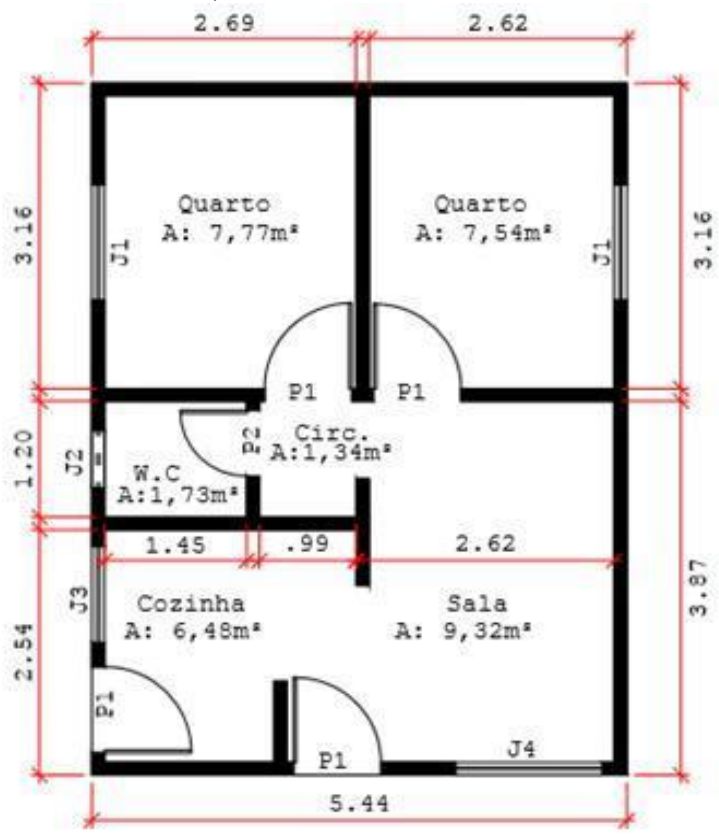

b) Cortes esquemáticos da HIS

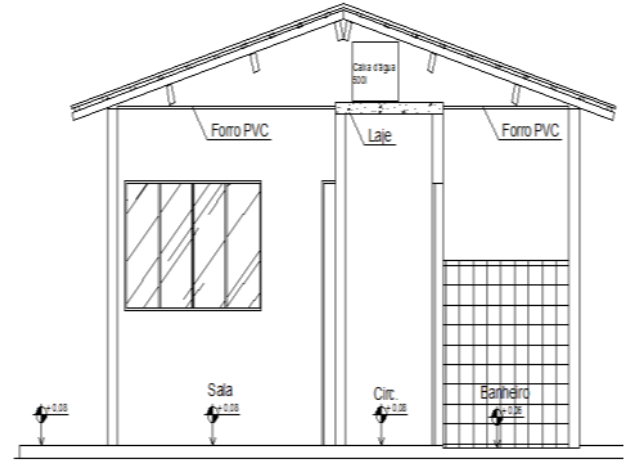

(b1) Transversal

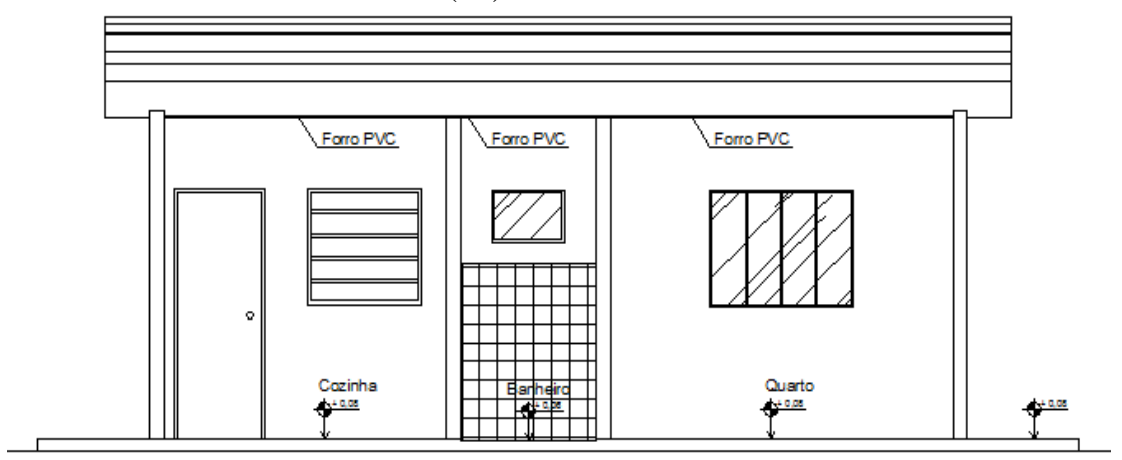

(b2) Longitudinal

Fonte: desenho com base em tipologia proposta Caixa Econômica Federal. 
Figura 2 - Zoneamento bioclimático brasileiro

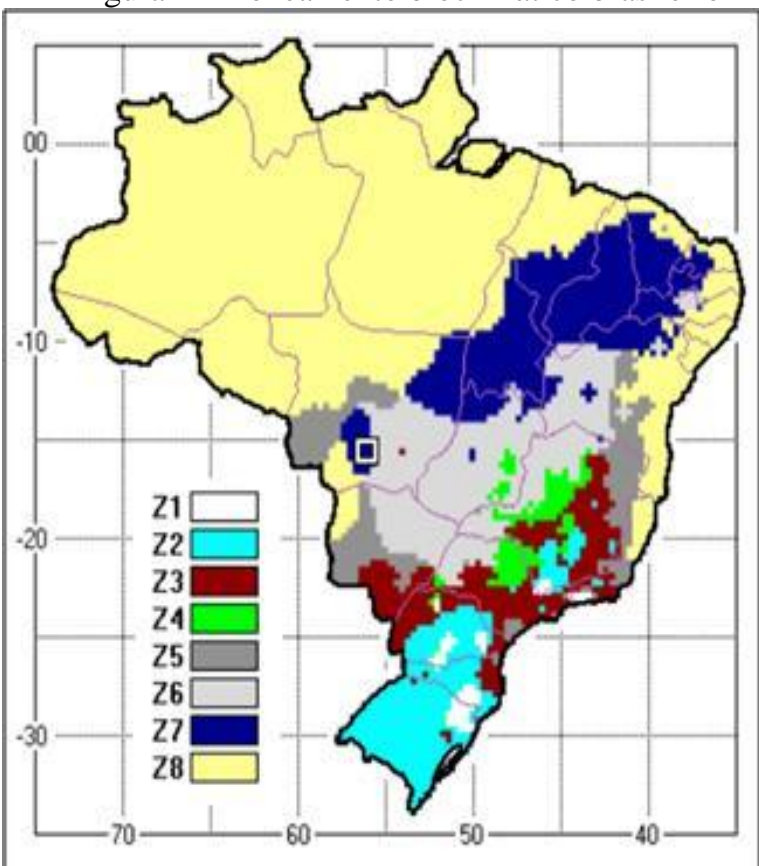

Fonte: NBR 15220 (ABNT, 2005a)
Figura 3 - Climas de Mato Grosso

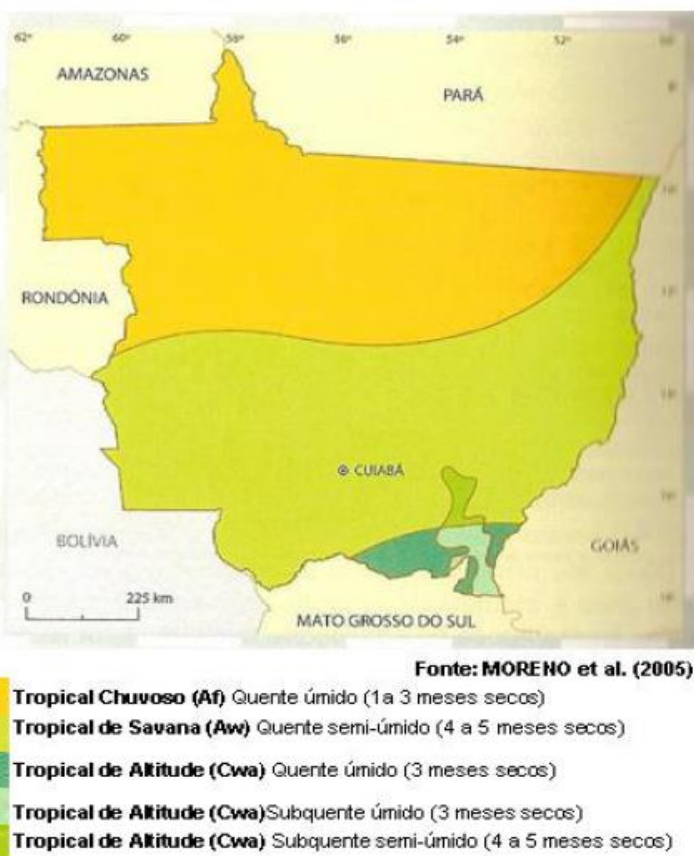

Fonte: MORENO et al. (2005)

Com base no trabalho de Rios (2015), identificou-se os materiais construtivos das paredes e cobertura e estabeleceu-se os valores de suas propriedades térmicas conforme a NBR 15.220-2 (ABNT, 2005b) e o Catálogo de Propriedades Térmicas de Paredes e Coberturas do Laboratório de Eficiência Energética em Edificações na versão cinco (LABEEE, 2011a).

Os percentuais efetivos de ventilação e iluminação proporcionados pelas tipologias de esquadrias foram definidos conforme o Anexo II do Regulamento Técnico da Qualidade para o Nível de Eficiência Energética de Edificações Residenciais (RTQ-R) (INMETRO, 2012), tendo sido adotados para a janela veneziana de correr de veneziana e vidro com quatro folhas (quartos e sala) e para a janela basculante (cozinha), fatores de ventilação (Fvent) iguais a 40 e $70 \%$ e fatores de iluminação (Filum) 70 e 65\%, respectivamente (Quadro 1). Para o ambiente da Sala-Cozinha, os valores de Fvent e Filum são os da média ponderada dos índices pelas áreas das janelas.

Quadro1 - Dimensões e áreas efetivas de ventilação e iluminação das janelas

\begin{tabular}{c|c|c|c|c|c|c}
\hline Ambiente & $\begin{array}{c}\text { Au } \\
\left(\mathbf{m}^{2}\right)\end{array}$ & $\begin{array}{c}\text { Largura } \\
(\mathbf{m})\end{array}$ & $\begin{array}{c}\text { Altura } \\
(\mathbf{m})\end{array}$ & Filum $^{2}$ & Fvent $^{3}$ & TIPO \\
\hline $\begin{array}{c}\text { Sala/ } \\
\text { Cozinha }\end{array}$ & 15,80 & 1,50 & 1,00 & \multirow{2}{*}{0,59} & 0,78 & $\begin{array}{c}\text { Veneziana com vidro (02 folhas fixas, 02 } \\
\text { folhas móveis) }\end{array}$ \\
\cline { 3 - 4 } & 1,00 & 1,00 & & & Basculante com vidro (02 folhas) \\
\hline Quarto 1 & 7,77 & 1,20 & 1,00 & 0,40 & 0,40 & $\begin{array}{c}\text { Veneziana com vidro (02 folhas fixas, 02 } \\
\text { folhas móveis) }\end{array}$ \\
\hline Quarto 2 & 7,54 & 1,20 & 1,00 & 0,40 & 0,40 & $\begin{array}{c}\text { Veneziana com vidro (02 folhas fixas, 02 } \\
\text { folhas móveis) }\end{array}$ \\
\hline
\end{tabular}


Guarda, Emeli L. A; et al; Estratégias Construtivas Para Adequação da Envoltória de uma Habitação de Interesse Social às Zonas Bioclimáticas Mato-Grossenses. E\&S - Engineering and Science, (2018), 7:1.

${ }^{1}$ Área útil do ambiente $;{ }^{2}$ Abertura líquida para iluminação proporcionada pela tipologia; ${ }^{3}$ Abertura líquida para ventilação proporcionada pela tipologia

Sabe-se que a orientação solar de uma edificação é determinante nas trocas térmicas e, por consequência, nas condições térmicas dos ambientes internos das edificações. Considerando que nos conjuntos residenciais, a HIS objeto de estudo pode ser implantada nas mais diversas orientações solares, trabalhou-se com a proposta de adequação bioclimática na condição de orientação mais desfavorável, ou seja, a que resulta na maior temperatura interna média anual no interior dos recintos da edificação. Nessa situação, ao se almejar proporcionar conforto térmico aos seus ocupantes por meio de condicionamento ativo, a demanda de nergia elétrica é maior. Assim, com base nos preceitos do RTQ-R, adotou-se neste trabalho a orientação mais desfavorável como sendo aquela em que a fachada principal da HIS objeto de estudo está voltada para o Sul, ou seja, com azimute $180^{\circ}$, conforme definido por RIOS (2015).

\subsection{Identificação dos pré-requisitos normativos de desempenho térmico e eficiência energética}

Para o estudo, inicialmente, foram avaliados os pré-requisitos da envoltória previstos na NBR 15220 (ABNT, 2005b), na NBR 15575 (ABNT, 2013) e no Regulamento Técnico da Qualidade do Nível de Eficiência Energética de Edifícios Residenciais (INMETRO, 2012), para as quatro zonas bioclimáticas de Mato Grosso, bem como as áreas mínimas de aberturas em relação à área de piso.

Na sequência, em caso de não enquadramento dos pré-requisitos estabelecidos nas normas elaboraram-se intervenções visando atendimento das recomendações e diretrizes construtivas de cada zona bioclimática.

As intervenções propostas para as quatro zonas visando atender aos pré-requisitos mínimos da NBR 15220/ NBR 15575 e RTQ-R seguiram a seguinte ordem de prioridades: (a) adequação da porcentagem de abertura líquida para ventilação e iluminação, por meio da alteração da tipologia das aberturas (alteração do fator Fvent e do fator de iluminação Filum); (b) possibilidade de sombreamento das aberturas (instalação de veneziana); (c) pintura da cobertura com cor clara (absortividade igual a 0,10, o que corresponde a cor branca) e pintura das paredes externas com cor clara (absortividade 0,10). Par adequar as transmitâncias térmicas do sistema de vedação vertical, foram agregados as paredes externas isolantes de poliestireno expandindo (EPS) na face externa da parede (Figura 4 -a2) e, para o sistema de cobertura, propôs-se a inserção de isolamentos térmicos abaixo da telha (Figura 4 - b3), bem como alterações no tipo de forro utilizado (Figura 4 - b4).

Atendidos os pré-requisitos em todas as zonas, procedeu-se à determinação da classificação de eficiência energética da envoltória para a HIS com as características construtivas alteradas, nas quatro zonas bioclimáticas de Mato Grosso. Utilizou-se o Método Prescritivo do Regulamento Técnico da Qualidade do Nível de Eficiência Energética de Edifícios Residenciais (INMETRO, 2012), quantificando-se o indicador de "Graus-Horas" de resfriamento $\left(\mathrm{GHR}\right.$, em $\left.{ }^{\circ} \mathrm{C}\right)$, determinado a partir da somatória da diferença da temperatura horária quando esta se encontra superior à temperatura de base $\left(26^{\circ} \mathrm{C}\right)(\mathrm{RTQ}-\mathrm{R}, 2012)$. $\mathrm{O}$ indicador GHR foi obtido diretamente da planilha de análise da envoltória para edificações residenciais pelo Método Prescritivo (LABEEE, 2012).

A cada adequação proposta ao projeto padrão, determinou-se novamente a classificação de eficiência energética da envoltória, comparando-se a classificação e os GrausHora de Resfriamento obtidos com as alterações implementadas. 
Guarda, Emeli L. A; et al; Estratégias Construtivas Para Adequação da Envoltória de uma Habitação de Interesse Social às Zonas Bioclimáticas Mato-Grossenses. E\&S - Engineering and Science, (2018), 7:1.

Figura 4: Sistemas de (a) vedação vertical e (b) de cobertura adotados no projeto padrão da HIS e nas propostas de intervenção para adequação às zonas bioclimáticas de Mato Grosso.

(a) Sistemas de vedação vertical

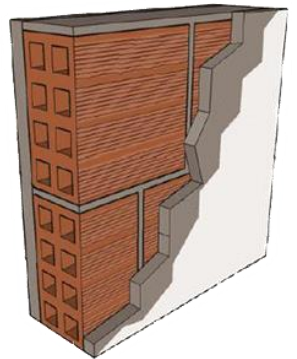

a1) Sistema padrão em alvenaria revestida interna e externamente por argamassa cimentícia.

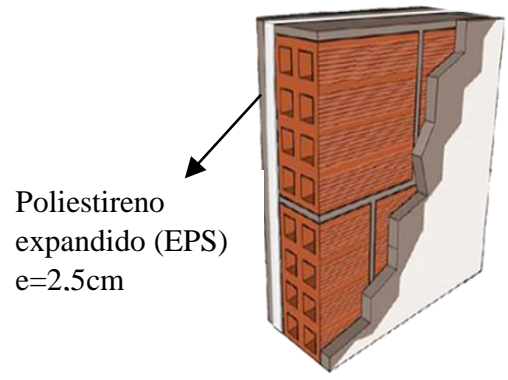

a2) Sistema com proposta de instalação de poliestireno expandido entre a argamassa e face externa da alvenaria.

b) Sistemas de cobertura

b1) Sistema em telha cerâmica, ático e forro de PVC.

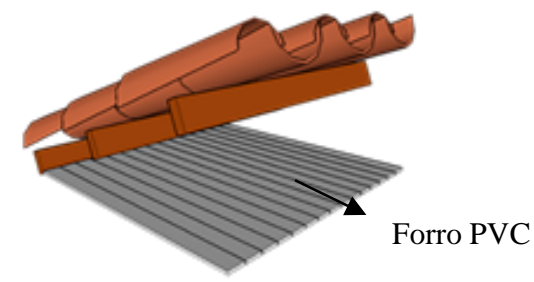

b3) Sistema com telha pintada em cor clara (sem ático) e manta isolante em Poliuretano

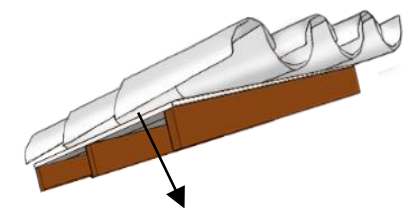

Manta isolante em Poliuretano $\mathrm{e}=0,5 \mathrm{~cm}+$ forro de PVC b2) Sistema com telha pintada em cor clara + ático e forro de PVC.

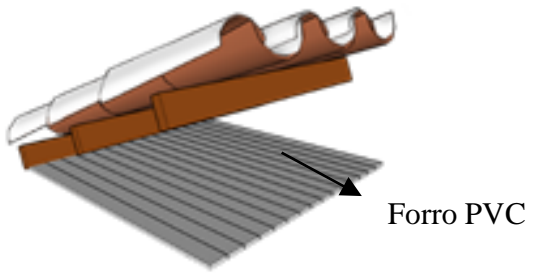

b4) Sistema em telha pintada em cor clara, ático e forro de madeira

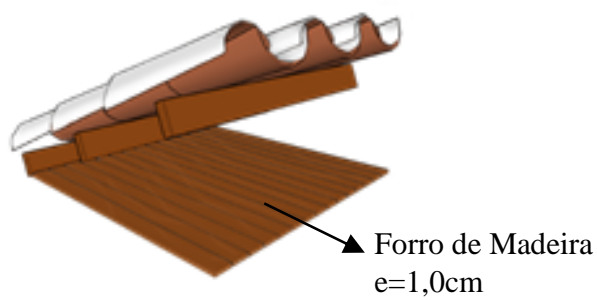

Fonte: adaptado de LABEE (2011a)

Destaca-se que as propostas de intervenções construtivas apresentadas na Figura 4 são passíveis de serem abarcadas nos projetos das HIS e, ainda, de serem aplicados nas edificações que já foram entregues aos usuários.

\section{RESULTADOS}

Todos os pré-requisitos de transmitância térmica, atraso térmico e fator solar da NBR 15220 (ABNT, 2005) avaliados a partir das propriedades termofísicas das paredes foram atendidas nas ZB 5 e 8, e nenhum deles nas ZB 6 e 7 (Quadro 2). As ZB 6 e 7 requerem inércia térmica pesada, que não é proporcionada pela parede da HIS padrão. 
Já para a NBR 15575 (ABNT, 2013) e para o RTQ-R (INMETRO, 2012), os prérequisitos são atendidos apenas nas ZB 7 e 8 . Nas ZB 5 e 6, a capacidade térmica do projeto padrão é insuficiente, o que significa que ela proporciona atrasos e amortecimentos insuficientes. Verifica-se também que os pré-requisitos entre as normas não são alinhados, sendo que a NBR 15220 é mais restritiva.

Quadro 2 - Comparação dos dados das paredes da HIS padrão com os pré-requisitos

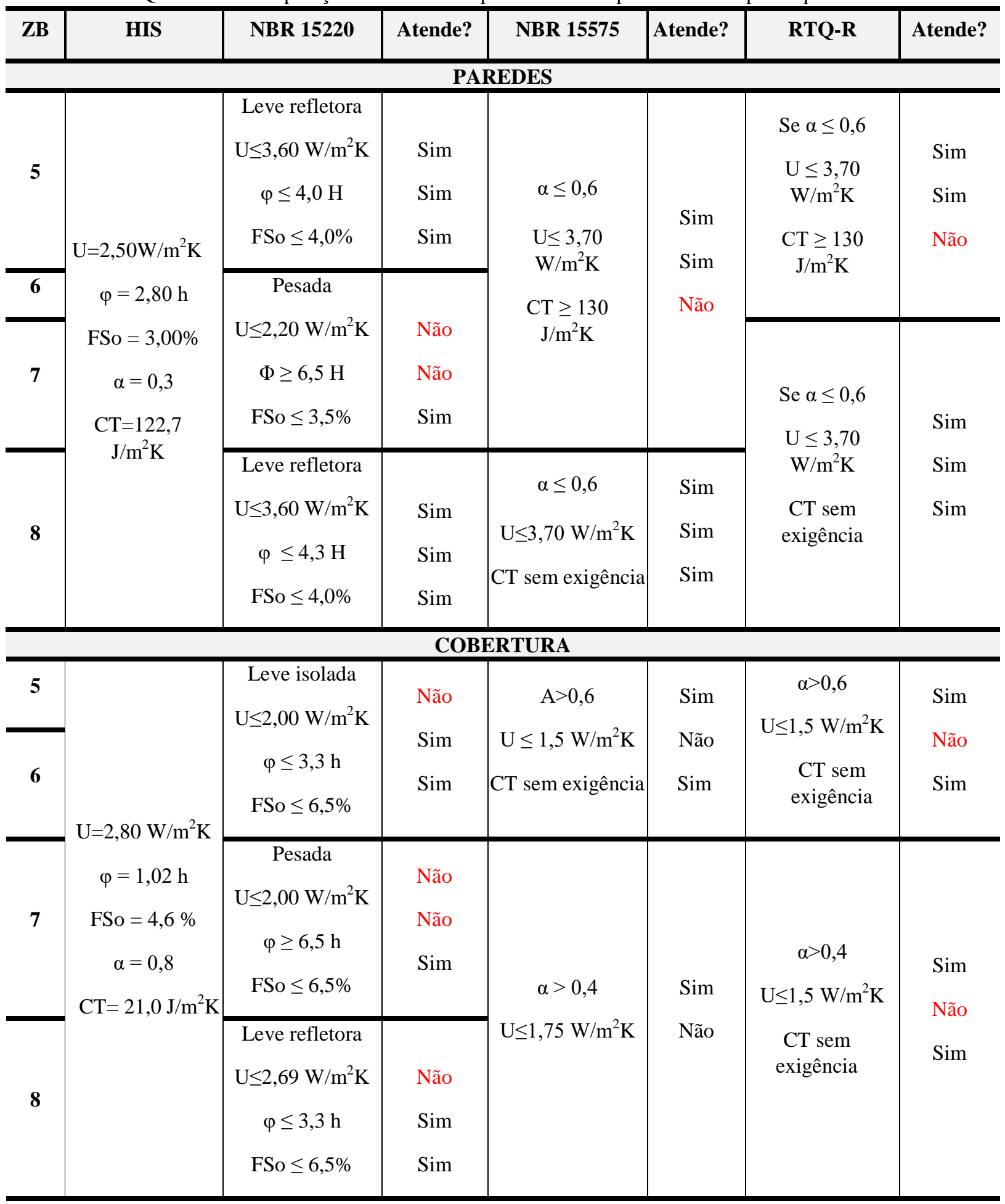

Fonte: NBR 15220 (ABNT, 2005), NBR 15575-4 (ABNT, 2013) e RTQ-R (INMETRO, 2012). 
Quanto à adequação da cobertura à NBR 15220 (ABNT, 2005a), o projeto padrão da HIS não é passível de adequação em nenhuma das zonas. Nas ZB 5, 6 e 8, a transmitância requerida é menor que a do projeto padrão, e na ZB 7, a transmitância e o atraso são menores. Já para os pré-requisitos da NBR 15575 (ABNT, 2013) e do RTQ-R (INMETRO, 2012), a transmitância térmica não é atendida para nenhuma das zonas. Dessa inadequação, resulta que a cobertura será responsável por elevados ganhos de calor interno.

Ao comparar a relação entre a área efetiva das esquadrias dos ambientes para ventilação e iluminação pelas respectivas áreas de piso da HIS padrão, verificou-se que os ambientes não atendem a nenhum dos pré-requisitos (Quadro 3), com exceção da SalaCozinha que atende ao requerido pela NBR 15575 (ABNT, 2013). Assim, para minimizar os impactos da adequação em termos de abertura de vão, foi proposta uma mesma alteração para as ZB 5, 6 e 7, que consistiu da alteração da tipologia para veneziana e vidro de abrir, com Fvent e Filum iguais a 0,9, considerando-se, também, que a veneziana externa proporciona sombreamento e permite o escurecimento do ambiente (variável sombreamento - somb - igual a 1 , no RTQ-R).

Quadro 3 - Comparação dos dados de iluminação e ventilação da HIS padrão com os pré-requisitos.

\begin{tabular}{|c|c|c|c|c|c|c|c|c|c|}
\hline \multirow{2}{*}{$\mathbf{Z B}$} & \multirow{2}{*}{$\begin{array}{l}\text { Ambi- } \\
\text { ente }\end{array}$} & \multirow{2}{*}{$\begin{array}{c}\mathbf{A v} / \mathbf{A u}^{1} \\
(\%)\end{array}$} & \multirow{2}{*}{$\begin{array}{c}\mathbf{A i} / \mathbf{A u}^{2} \\
(\%)\end{array}$} & \multicolumn{4}{|c|}{ \% da área de piso requerida para ventilação } & \multicolumn{2}{|c|}{$\begin{array}{l}\text { \% da área de piso } \\
\text { requerida } \\
\text { ventilação e iluminação }\end{array}$} \\
\hline & & & & NBR $15220^{3}$ & $\begin{array}{c}\text { Atende } \\
?\end{array}$ & $\begin{array}{c}\text { NBR } \\
15575-4\end{array}$ & $\begin{array}{c}\text { Atende } \\
?\end{array}$ & RTQ-R & Atende? \\
\hline $\begin{array}{l}5 \\
6 \\
\end{array}$ & \multirow{3}{*}{$\begin{array}{l}\text { Sala/ } \\
\text { cozinha }\end{array}$} & \multirow{3}{*}{8,23} & \multirow{3}{*}{6,65} & $15 \%<\mathrm{A}<25 \%$ & \multirow{3}{*}{ Não } & \multirow{2}{*}{$\mathrm{A}>7 \%$} & \multirow{2}{*}{ Sim } & $\begin{array}{c}\mathrm{Av}>8 \% \\
\mathrm{Ai}>12,5 \%\end{array}$ & $\begin{array}{l}\text { Sim } \\
\text { Não }\end{array}$ \\
\hline 7 & & & & $10 \%<\mathrm{A}<15 \%$ & & & & $\begin{array}{c}\mathrm{Av}>5 \% \\
\mathrm{Ai}>12,5 \%\end{array}$ & $\begin{array}{l}\text { Sim } \\
\text { Não }\end{array}$ \\
\hline 8 & & & & $A>40 \%$ & & $\mathrm{~A}>12 \%$ & Não & $\begin{array}{c}\mathrm{Av}>10 \% \\
\mathrm{Ai}>12,5 \%\end{array}$ & $\begin{array}{l}\text { Não } \\
\text { Não }\end{array}$ \\
\hline $\begin{array}{l}5 \\
6 \\
\end{array}$ & \multirow{3}{*}{$\begin{array}{c}\text { Quarto } \\
1\end{array}$} & \multirow{3}{*}{6,18} & \multirow{3}{*}{6,18} & $15 \%<\mathrm{A}<25 \%$ & \multirow{3}{*}{ Não } & \multirow{2}{*}{$\mathrm{A}>7 \%$} & \multirow{2}{*}{ Sim } & $\begin{array}{c}\mathrm{Av}>8 \% \\
\mathrm{Ai}>12,5 \%\end{array}$ & $\begin{array}{l}\text { Não } \\
\text { Não } \\
\end{array}$ \\
\hline 7 & & & & $10 \%<\mathrm{A}<15 \%$ & & & & $\begin{array}{c}\mathrm{Av}>5 \% \\
\mathrm{Ai}>12,5 \%\end{array}$ & $\begin{array}{l}\text { Sim } \\
\text { Não }\end{array}$ \\
\hline 8 & & & & $\mathrm{~A}>40 \%$ & & $\mathrm{~A}>12 \%$ & Não & $\begin{array}{c}\mathrm{Av}>10 \% \\
\mathrm{Ai}>12,5 \%\end{array}$ & $\begin{array}{l}\text { Não } \\
\text { Não }\end{array}$ \\
\hline $\begin{array}{l}5 \\
6 \\
\end{array}$ & \multirow{3}{*}{$\begin{array}{c}\text { Quarto } \\
2\end{array}$} & \multirow{3}{*}{6,37} & \multirow{3}{*}{6,37} & $15 \%<\mathrm{A}<25 \%$ & \multirow{3}{*}{ Não } & \multirow{2}{*}{$\mathrm{A}>7 \%$} & \multirow{2}{*}{ Sim } & $\begin{array}{c}\mathrm{Av}>8 \% \\
\mathrm{Ai}>12,5 \%\end{array}$ & $\begin{array}{l}\text { Não } \\
\text { Não }\end{array}$ \\
\hline 7 & & & & $10 \%<\mathrm{A}<15 \%$ & & & & $\begin{array}{c}\mathrm{Av}>5 \% \\
\mathrm{Ai}>12,5 \%\end{array}$ & $\begin{array}{l}\text { Sim } \\
\text { Não }\end{array}$ \\
\hline 8 & & & & $\mathrm{~A}>40 \%$ & & $\mathrm{~A}>12 \%$ & Não & $\begin{array}{c}\mathrm{Av}>10 \% \\
\mathrm{Ai}>12,5 \%\end{array}$ & $\begin{array}{l}\text { Não } \\
\text { Não }\end{array}$ \\
\hline
\end{tabular}

Fonte: autores

Para a ZB8, que exige áreas de ventilação maior que $40 \%$ da área de piso, as áreas tiveram que ser aumentadas, passando-se as janelas da Sala e Quartos para portas balcão, além de aumentar suas larguras (Quadro 4). Mesmo com divergências entre as normativas, pode-se concluir que a iluminação e a ventilação proporcionada pelas aberturas da HIS padrão é insuficiente.

\footnotetext{
${ }^{1} 1 \mathrm{Av}$ : área líquida de abertura para ventilação $\left(\mathrm{m}^{2}\right) .2$ Ai: área líquida de abertura para iluminação $\left(\mathrm{m}^{2}\right) .3$ Sombrear aberturas.
} 
Guarda, Emeli L. A; et al; Estratégias Construtivas Para Adequação da Envoltória de uma Habitação de Interesse Social às Zonas Bioclimáticas Mato-Grossenses. E\&S - Engineering and Science, (2018), 7:1.

Quadro 4 - Dimensões alteradas de áreas efetivas de ventilação e iluminação das janelas

\begin{tabular}{|c|c|c|c|c|c|c|c|c|}
\hline $\mathbf{Z B}$ & Ambiente & $\begin{array}{l}\mathrm{Au} \\
\left(\mathbf{m}^{2}\right)\end{array}$ & $\begin{array}{l}\mathbf{A b}^{2} \\
\left(\mathbf{m}^{2}\right)\end{array}$ & $\begin{array}{c}\text { Largura } \\
\text { (m) }\end{array}$ & $\begin{array}{c}\text { Altura } \\
\text { (m) }\end{array}$ & Filum & $\begin{array}{c}\mathbf{A} / \mathbf{A v} \mathbf{v}^{1} \\
(\%)\end{array}$ & TIPO \\
\hline \multirow{4}{*}{8} & \multirow{2}{*}{ Sala/cozinha } & \multirow{2}{*}{15,8} & 3,3 & 2,1 & \multirow{2}{*}{0,8} & \multirow{2}{*}{0,8} & \multirow{2}{*}{$40,15 \%$} & veneziana e vidro, abrir 4 folhas \\
\hline & & & 1,0 & 1,0 & & & & veneziana e vidro, abrir 2 folhas \\
\hline & Quarto 1 & 7,77 & 1,85 & 2,1 & 0,8 & 0,8 & $40,00 \%$ & veneziana e vidro, abrir 4 folhas \\
\hline & Quarto 2 & 7,54 & 1,80 & 2,1 & 0,8 & 0,8 & $40,11 \%$ & veneziana e vidro, abrir 4 folhas \\
\hline
\end{tabular}

${ }^{1}$ Porcentagem da área líquida de abertura de ventilação e iluminação em relação à área de piso.

2 Área final das aberturas

Fonte: autores

Em todas as zonas, a pintura externa das paredes deve ser de cor clara, com absortância igual ou inferior a 0,10 (Quadro 5).

As adequações nas paredes da ZB5 consistiram de colocação de placas de poliestireno expandido de $2,5 \mathrm{~cm}$ de espessura na face externa dos blocos cerâmicos com reboco externo de 1,5cm. Em caso de HIS já construída, as placas e reboco podem ser aplicados sobre o reboco existente, o que proporcionará igual adequação. Na cobertura, o pé-direito da SalaCozinha foi aumentado para $3,35 \mathrm{~m}$, o que equivale a executar novo forro, acompanhando a inclinação da cobertura, sendo necessária a colocação de manta isolante térmica entre o forro de PVC e as telhas, de 0,5cm de espessura (Quadro 5).

Nas ZB 6 e 7, considerando-se as argamassas de reboco externa e interna com 2,5cm de espessura, é possível adequar a tipologia das paredes à zona. Na ZB6, não são necessárias intervenções na cobertura e na ZB7, há que se trocar o forro de PVC por madeira $1 \mathrm{~cm}$. Na ZB8, as paredes e coberturas devem ser semelhantes à da ZB 5 (Quadro 6).

Quadro 5 - Alterações dos materiais das paredes da HIS padrão para cada uma das zonas bioclimáticas.

\begin{tabular}{|c|c|c|c|c|c|c|c|}
\hline $\mathbf{Z B}$ & HIS padrão & $\begin{array}{c}\mathbf{C T} \\
\left(\mathbf{K J} / \mathbf{m}^{2} \mathbf{K}\right. \\
)\end{array}$ & $\begin{array}{c}\mathbf{U} \\
\left(\mathbf{W} / \mathbf{m}^{2} \mathbf{K}\right)\end{array}$ & HIS parede alterada & $\begin{array}{c}\mathbf{C T} \\
\left(\mathbf{K} \mathbf{J} / \mathbf{m}^{2} \mathbf{K}\right)\end{array}$ & $\begin{array}{c}\mathbf{U} \\
\left(\mathbf{W} / \mathbf{m}^{2} \mathbf{K}\right)\end{array}$ & $\begin{array}{c}\text { Observaçõe } \\
\text { s }\end{array}$ \\
\hline 5 & \multirow{4}{*}{$\begin{array}{c}\text { Argamassa } \\
2 \mathrm{~cm} \\
+ \\
\text { Bloco } \\
\text { cerâmico } \\
9 \times 19 \times 19 \mathrm{~cm} \\
+ \\
\text { Argamassa } 2 \\
\mathrm{~cm}\end{array}$} & \multirow{4}{*}{122,70} & \multirow{4}{*}{2,50} & $\begin{array}{l}\text { Argamassa } 1,5 \mathrm{~cm}+ \\
\text { Poliestireno expandido } \\
(\text { EPS) 2,5cm }+ \text { Bloco } \\
\text { cerâmico 9x19x19cm + } \\
\text { Argamassa } 2 \mathrm{~cm}\end{array}$ & 154,00 & 1,00 & \multirow{4}{*}{$\begin{array}{l}\text { Tipologia } \\
\text { janelas = } \\
\text { venezianas } \\
\text { e vidro, } \\
\text { abrir } 4 \\
\text { folhas }\end{array}$} \\
\hline 6 & & & & $\begin{array}{lr}\text { Argamassa } & 2,5 \mathrm{~cm}+ \\
\text { Bloco } & \text { cerâmico } \\
9 \times 19 \times 19 \mathrm{~cm} & \text { Argamassa } \\
2,5 \mathrm{~cm} & \end{array}$ & 142,70 & 2,50 & \\
\hline 7 & & & & $\begin{array}{l}\text { Argamassa } 2,5 \mathrm{~cm}+ \\
\text { Bloco }+ \\
9 \times 19 \times 19 \mathrm{~cm}+\text { Argamassa } \\
2,5 \mathrm{~cm}\end{array}$ & 142,70 & 2,50 & \\
\hline 8 & & & & $\begin{array}{l}\text { Argamassa } 1,5 \mathrm{~cm}+ \\
\text { Poliestireno expandido } \\
\text { EPS 2,5cm }+ \text { Bloco } \\
\text { cerâmico 9x19x19cm + } \\
\text { argamassa } 2 \mathrm{~cm}\end{array}$ & 154,10 & 1,00 & \\
\hline
\end{tabular}

Fonte: autores 
Guarda, Emeli L. A; et al; Estratégias Construtivas Para Adequação da Envoltória de uma Habitação de Interesse Social às Zonas Bioclimáticas Mato-Grossenses. E\&S - Engineering and Science, (2018), 7:1.

Quadro 6 - Alterações dos materiais e pé-direito da cobertura da HIS padrão para cada uma das zonas bioclimáticas.

\begin{tabular}{|c|c|c|c|c|c|c|c|}
\hline \multicolumn{8}{|c|}{ COBERTURA } \\
\hline 5 & \multirow{4}{*}{$\begin{array}{l}\text { Telha cerâmica } \\
\qquad 1 \mathrm{~cm} \\
+ \\
\text { Câmara de ar de } \\
\text { fluxo vertical } \\
+ \\
\text { Forro PVC } 1 \mathrm{~cm}\end{array}$} & \multirow{4}{*}{21,00} & \multirow{4}{*}{1,80} & $\begin{array}{l}\text { Telha cerâmica } \mathrm{cm}+ \\
\text { Poliuretano } 0.5 \mathrm{~cm}+ \\
\text { Câmara de ar de fluxo } \\
\text { vertical + Forro PVC } 1 \mathrm{~cm}\end{array}$ & 21,30 & 1,90 & $\begin{array}{l}\text { Pé direito } \\
\text { Sala- } \\
\text { Cozinha }= \\
3,35 \mathrm{~m}\end{array}$ \\
\hline 6 & & & & $\begin{array}{l}\text { Telha cerâmica } 1 \mathrm{~cm}+ \\
\text { Câmara de ar de fluxo } \\
\text { vertical }+ \text { Forro PVC } 1 \mathrm{~cm}\end{array}$ & 21,0 & 1,80 & - \\
\hline 7 & & & & $\begin{array}{l}\text { Telha cerâmica } 1 \mathrm{~cm}+ \\
\text { Câmara de ar de fluxo } \\
\text { vertical }+ \text { Forro madeira } \\
1 \mathrm{~cm}\end{array}$ & 26,40 & 2,00 & - \\
\hline 8 & & & & $\begin{array}{l}\text { Telha cerâmica } 1 \mathrm{~cm}+ \\
\text { Poliuretano } 0,5 \mathrm{~cm}+ \\
\text { Câmara de ar de fluxo } \\
\text { vertical + Forro PVC } 1 \mathrm{~cm}\end{array}$ & 21,30 & 1,90 & $\begin{array}{l}\text { Pé direito } \\
\text { Sala- } \\
\text { Cozinha = } \\
\text { 3,35m }\end{array}$ \\
\hline
\end{tabular}

Fonte: autores

A análise da eficiência energética pelo RTQ-R indicou que a tipologia padrão classificava-se em D nas ZB 5 e 8 e em D, nas ZB 6 e 7 (Quadro 7). Com as adequações propostas, realizou-se a reclassificação da eficiência energética da envoltória, por meio da qual se alcançou nível de eficiência A em todas as zonas bioclimáticas do estado.

Quadro 7 - Comparação de eficiência energética da HIS padrão para cada zona bioclimáticas.

\begin{tabular}{|c|c|c|c|c|}
\hline $\mathbf{Z B}$ & $\begin{array}{r}\text { Valores obtidos } \\
\text { Resultados } \\
\end{array}$ & $\begin{array}{l}\text { imulações e } \\
\text { aliações }\end{array}$ & $\begin{array}{c}\text { HIS } \\
\text { padrão }\end{array}$ & $\begin{array}{c}\text { HIS } \\
\text { eficiente }\end{array}$ \\
\hline \multirow{2}{*}{5} & \multicolumn{2}{|c|}{$\overline{G H R}$} & 12.392 & 5.084 \\
\hline & Classificação & $\mathrm{EqN}$ & D 2,24 & \begin{tabular}{l|l} 
A & 4,75
\end{tabular} \\
\hline \multirow{2}{*}{6} & \multicolumn{2}{|c|}{$\mathrm{GHR}$} & 7.395 & 1.207 \\
\hline & ıção & $\mathrm{Eql}$ & 3,00 & 5,00 \\
\hline & \multicolumn{2}{|c|}{$\mathrm{GHR}$} & 22.031 & 12.358 \\
\hline & Classificação & EqNumEnv & C 3,00 & \begin{tabular}{l|l} 
A & 4,51 \\
\end{tabular} \\
\hline & \multicolumn{2}{|c|}{$\overline{\mathrm{GHR}}$} & 12.392 & 5.084 \\
\hline & Classificação & EqNumEnv & 2,24 & 4,75 \\
\hline
\end{tabular}

Fonte: autores

Ressalta-se que as alterações propostas podem ser facilmente implementadas durante a fase de projeto das HIS, sendo ainda passíveis de adotadas durante a reforma e/ou adequação da edificação. Com ressalvas para a ZB 8, que exige aberturas muito maiores que a da HIS padrão, pode-se inferir que as medidas sugeridas são viáveis tendo em vista a efetividade da reclassificação da eficiência energética da envoltória do projeto pesquisado. 
Guarda, Emeli L. A; et al; Estratégias Construtivas Para Adequação da Envoltória de uma Habitação de Interesse Social às Zonas Bioclimáticas Mato-Grossenses. E\&S - Engineering and Science, (2018), 7:1.

\section{CONCLUSÃO}

Este artigo se propôs a realizar um levantamento dos pré-requisitos dos materiais das paredes e coberturas, bem como das áreas de iluminação e ventilação, de uma HIS padrão construída em todo o território estadual, verificando a sua adequação às zonas $5,6,7$ e 8 contidas no estado.

Focando-se na premissa de propor soluções de adequação de baixo impacto nas especificações originais, foi possível com aumento da espessura do reboco nas ZB 5, 6 e 7 e inserção de material isolante na $\mathrm{ZB} 8$, promover atendimento às recomendações normativas. $\mathrm{Na}$ cobertura, as intervenções foram a inserção de manta isolante com alteração da posição do forro para aumento do pé-direito nas ZB 5 e 8 e adoção de forro de madeira na ZB7.

Destaca-se o importante papel das aberturas para ventilação e iluminação, as quais necessitaram sofrer alterações em termos de tipologia com intuito de adequar o edifício às necessidades de cada zona bioclimática, sendo que na ZB 8, além da tipologia, houve a necessidade de se alterar os vãos das mesmas com intuito de atender uma relação área de abertura e área de piso do ambiente de $40 \%$.

Todas as adequações propostas permitiram que a eficiência envoltória da edificação se elevasse do nível D ou C para A de acordo com Regulamento Técnico da Qualidade do Nível de Eficiência Energética de Edifícios Residenciais, de onde se conclui que, caso os requisitos normativos tivessem sido observados na etapa de projeto, ter-se-ia uma habitação de melhor qualidade e mais eficiente em termos de consumo de energia para resfriamento, ou seja, mais sustentável na fase de uso.

Sugere-se para estudos futuros, o aprofundamento do desempenho térmico e de eficiência energética da HIS, por meio de simulações computacionais, avaliando, também, as condições de conforto térmico e lumínico por elas proporcionadas.

\section{REFERÊNCIAS}

ASSOCIAÇÃO BRASILEIRA DE NORMAS TÉCNICAS (ABNT). NBR 15220-2: Desempenho térmico de edificações - Método de cálculo da transmitância térmica, da capacidade térmica, do atraso térmico e do fator solar de elementos e componentes de edificações. Rio de Janeiro, 2005a.

. NBR 15220-3: Desempenho térmico de edificações - Zoneamento bioclimático brasileiro e diretrizes construtivas para habitações unifamiliares de interesse social. Rio de Janeiro, 2005b.

Janeiro, 2013.

NBR 15575-1: Edificações habitacionais - Desempenho - Requisitos gerais. Rio de

ÁlVARES, C. A.; STAPE, J. L.; SENTElHAS, P. C.; GONÇALVES. J. L. M.; SPAROVEK, G. Köppen's climate classification map for Brazil. Meteorologische Zeitschrift, v. 22, n. 6, p.711-728, 2014.

ASSIS, E. S.; PEREIRA, E. M. D.; SOUZA, R. V. G.; DINIZ, A. S. A. C. Habitação social e eficiência energética: um protótipo para o clima de Belo Horizonte. In: II Congresso Brasileiro de Eficiência Energética - IICBEE, Vitória, 2016. Anais...Vitória, 2016.

\section{CLÍMACO, R; AMORIM, C. Princípios Bioclimáticos da Arquitetura e do Urbanismo.}

Brasília: UNB, 2008. Plano de Curso, UNB, 2008. 
Guarda, Emeli L. A; et al; Estratégias Construtivas Para Adequação da Envoltória de uma Habitação de Interesse Social às Zonas Bioclimáticas Mato-Grossenses. E\&S - Engineering and Science, (2018), 7:1.

DURANTE, L. C., NOGUEIRA, M. C. J. A. SANCHES, J. C. Habitação de interesse social - aspectos de conforto térmico e recomendações de projeto para Cuiabá/MT. Cuiabá: CEFET/MT, v.150, p.62, 2006.

FRANÇA, J. M.; CRUCINSKY, V. M. P. Conceitos de bioclimatologia e sustentabilidade aplicados ao projeto arquitetônico residencial e avaliação do conforto térmico e lumínico da edificação. 2010. 233 f. Trabalho de Conclusão de Curso - Engenharia de Produção Civil, Universidade Tecnológica Federal do Paraná. Curitiba, 2010.

INSTITUTO NACIONAL DE METROLOGIA, QUALIDADE E TECNOLOGIA INMETRO. Portaria $n^{\circ} 449$, de 25 de novembro de 2010. Aprovar o Regulamento Técnico da Qualidade - RTQ para o Nível de Eficiência Energética de Edificações Residenciais. Diário Oficial [da] República Federativa do Brasil, Rio de Janeiro, 17 jan. 2012.

LAMBERTS, Roberto; DUTRA, Luciano; PEREIRA, Fernando O. R. Eficiência Energética na Arquitetura. $3^{\text {a }}$ Edição, São Paulo: PW, 2014.

MARAFON, C.; LACO, MIRIAN; SANCHES, J. C. M.; LEÃO, M.; LEÃO, E. F. T. B. Estratégias bioclimáticas em avaliação de desempenho térmico nas habitações de interesse social em Sinop/MT. Revista Eletrônica em Gestão, Educação e Tecnologia Ambiental REGET, v. 18, n. 3, p.1008-1021, 2014.

MORENO, A. C. R. Minha Casa Minha Vida: análise de desempenho térmico pela NBR 15.220-3, NBR 15.575, Selo Casa Azul e RTQ-R. Dissertação (Mestrado em Ambiente Construído e Patrimônio Sustentável), UFMG, 2015.

OLARTECHEA, M. S.; CALLEJAS, I. J. A.; DURANTE, L. C.; ROSSETI, K. Andrade C.; LIMA, M. J. S. Impactos da incorporação de diretrizes construtivas bioclimáticas no desempenho termoenergético de habitação de interesse social (ZB 07). In: XIII Encontro Nacional e IX Encontro Latino-americano de Conforto no Ambiente Construído, 2015, Campinas. XIII Encontro Nacional e IX Encontro Latino-americano de Conforto no Ambiente Construído, v. 1, p. 1-9, 2015.

PASSOS, I. C. S.; DAMASCENO, S. R. G.; BARBIRATO, G. M. Desempenho térmico de habitações térreas de interesse social em Maceió-AL: simulações de alternativas de reformas para diferentes orientações e estimativas de conforto térmico de usuários. In: XII Encontro Nacional de Tecnologia do Ambiente Construído, 2008, Fortaleza. Anais...Fortaleza, 2008.

RIOS, Gisele Auxiliadora de Almeida. Desempenho termoenergético de habitação de interesse social. Tese (Doutorado), Universidade Estadual Paulista. Faculdade de Engenharia de Ilha Solteira. Área de conhecimento: automação, 2015.

ROTTA, R. Desempenho térmico de edificações multifamiliares de interesse social em conjuntos habitacionais na cidade de Santa Maria - RS. 131p. Dissertação (Mestrado). Programa de Pós-Graduação em Engenharia Civil. Centro de Tecnologia. Universidade Federal de Santa Maria. Santa Maria - RS, 2009. 